Research Article

\title{
Characteristics of the Near-Ground Typhoon Morakot
}

\author{
Yanru Wang $\mathbb{D},{ }^{1}$ Yongguang Li $\mathbb{D},{ }^{2}$ Bin Fu $\mathbb{D},{ }^{1}$ Xu Wang $\left(\mathbb{D},{ }^{2}\right.$ Chuanxiong Zhang $\mathbb{D},{ }^{3}$ and \\ Guangyu Fan iD 1 \\ ${ }^{1}$ School of Civil Engineering, Taizhou University, Taizhou 318000, China \\ ${ }^{2}$ State Key Laboratory of Mountain Bridge and Tunnel Engineering, Chongqing Jiaotong University, Chongqing 400074, China \\ ${ }^{3}$ School of Civil Engineering, Wenzhou University, Wenzhou 150080, China
}

Correspondence should be addressed to Bin Fu; dorofubin@tzc.edu.cn

Received 30 March 2021; Accepted 29 August 2021; Published 26 September 2021

Academic Editor: Marco Miniaci

Copyright (C) 2021 Yanru Wang et al. This is an open access article distributed under the Creative Commons Attribution License, which permits unrestricted use, distribution, and reproduction in any medium, provided the original work is properly cited.

Two WJ-3 anemometers placed at the same height on the top of an architectural engineering building in Wenzhou University are used to determine the wind speed of Typhoon Morakot during its landing in real time. This study aims to explore Typhoon Morakot's wind field characteristics, including mean wind speed, probability density distribution of fluctuating wind speed, power spectral density, correlation analysis, and coherence, on the basis of data measured by the two anemometers. Results show that the probability density distribution of the fluctuating wind speed of the typhoon follows the Gaussian distribution, and the measured cross-power spectrum of fluctuating wind speed is in good agreement with the modified Karman spectrum. The autocorrelation decreases with the increase in time interval $(\tau)$. The longitudinal autocorrelation coefficient decays rapidly with the increase in $\tau$, and the lateral autocorrelation coefficient decays at an unchanged rate. The exponential attenuation coefficients of the longitudinal and transverse fluctuating wind speeds increase with the increase in the mean wind speed, and their mean values are 10.86 and 15.33, respectively. The change trends of the coherence coefficients of the two wind speed components with the mean wind speed are the same. The measured coherence coefficients of the two wind speed components are in good agreement with the exponential function.

\section{Introduction}

Statistics show that the loss caused by wind disasters ranks first amongst losses arising from all kinds of natural disasters [1]. The collapse of houses under strong wind conditions is the primary cause of property damage and casualties [2]. Studying wind disaster mechanisms and wind field characteristics is important for improving the antiwind performance of structures and reducing property damage and casualties [3-5]. Scholars at home and abroad have conducted extensive research on near-ground wind to master the mechanism of wind disasters. So far, several methods could be used to measure wind characteristics, which are mostly field test [6-8], numerical simulation $[9,10]$, and wind tunnel test [11-13]. Nowadays, these methods are applied in many studies.

Since bridges become more and more complicated with the increasing long spans, the operability and controllability of numerical simulation are more and more prominent. Computational fluid dynamics (CFD) is an effective method used to analyse wind characteristics [14]; the simulation method is rapidly developing and widely used in wind characteristics $[15,16]$. CFD simulation was carried out by Baghaei Daemei et al. to reduce drag coefficient performance of aerodynamic modification approaches. The results showed that modification of rounded corners was able to cause a reduction in the drag coefficient [17]. The accuracy of numerical simulation results depended on whether the numerical inflow boundary conditions match the mean and turbulent inflow conditions in the CFD method [18]. Li et al. carried out a numerical simulation for the wind characteristics of bridge site with complex terrain and provided a basis for the determination of design wind speed of the bridge [19]. Wind tunnel test and CFD simulation were conducted to study the wind characteristics at a bridge site in mountainous terrain, and the results of these two methods 
were compared [20]. Zhang et al. studied the influence of thermal effects on the wind characteristics at a bridge in a deep-cutting gorge with high-altitude and temperature difference in FLUENT. Results showed that the surface temperature distribution of the bridge was uneven under different temperatures [21]. Taking the surface conditions of a hill as an object, Tamura et al. used the large-eddy simulation (LES) method to study the turbulent boundary-layer flows over a hill and studied the influence of vegetation on turbulence statistics [14]. In addition, many scholars investigated wind characteristics and wind pressure via wind tunnel tests. A mountain terrain model with a scale of 1 : 2000 was built, and wind characteristics were carried out using wind tunnel tests [22]. By a combination of wind tunnel tests and numerical simulation, the profiles of wind speed and turbulence intensity varied with terrains were proved [23]. Li et al. built a terrain model with a scale of 1 : 1000 and studied wind characteristics with the method of wind tunnel tests, and the results showed that the incoming wind direction affected the wind characteristics [24]. Besides, to measure the unsteady aerodynamic force on a galloping prism and galloping response, HAPB (hybrid aeroelastic-pressure balance) wind tunnel tests were performed by Chen et al. [25]. The wind tunnel test of a tapered model showed that wind pressure distributions and unsteady force coefficients have different characteristics at low and high wind speeds and found a novel and unique phenomenon-termed partial reattachment $[26,27]$. In these previously mentioned studies, most of these produced good results. However, as the most direct method, field measurements are essential for understanding the wind characteristics of a bridge site and are adopted by many scholars.

Comparing the numerical simulation methods, field measurements have been regarded as a reliable method to provide accurate evaluations of wind effects [28]. Huang et al. [29] conducted a comparative analysis of the nearground fluctuating power spectrum of Pudong, Shanghai, under typhoon and monsoon action. The analysis results showed that the change trends of the attenuation coefficients of the coherence index of the fluctuating wind component under typhoon and monsoon action are consistent with the change in the mean wind speed. Cao et al. [30] analysed data synchronously measured by several anemometers at the same position. Results showed that when the wind speed is low, turbulence intensity decreases with the increase in mean wind speed. Turbulence intensity ceases to change with further increments in wind speed, and the measured power spectrum of fluctuating wind speed is in good agreement with the Karman spectrum only at a low frequency. Miyata et al. [31], using the measured data of Nos. 9807 and 9918 typhoons, analysed the power spectral density of longitudinal fluctuating wind speed and spatial coherence. Li et al. [32] explored the wind characteristic parameters at the site of Sutong Bridge by using measured data. They discovered that the ratio of longitudinal-to-transverse turbulence intensity is larger than the empirical value. Pang et al. [33] studied near-ground wind characteristics in Pudong, Shanghai, on the basis of a 3D ultrasonic wind speed sample measured at a height of $20 \mathrm{~m}$ and discovered that turbulence intensity and gust factor are high near the ground. Li et al. [34] explored the wind load characteristics of low buildings and the wind field characteristics of a strong typhoon before and after landing. The results showed that turbulence intensity and gust factor decrease significantly after typhoon landing, and the power spectral density of the fluctuating wind component is consistent with the Von Karman empirical spectrum. However, existing research results are against the wind field characteristics of low buildings. Most high-rise buildings in the coastal cities of China frequently suffer from typhoon disasters. Research on the field characteristics of high-rise buildings is rare, which is unfavourable for the wind resistance design of coastal structures.

In this study, the wind speed of Typhoon Morakot was obtained in real time for a duration of $13 \mathrm{~h}$ by using the topmost part of a construction engineering building in Wenzhou University as the observation site. The typhoon's wind field characteristics, including mean wind speed, turbulence intensity, gust factor, peak factor, fluctuating wind speed power spectral density, and coherence, were analysed.

\section{Typhon Morakot and Measurement Procedure}

Typhoon No. 8 named "Morakot" was generated on August 4, 2009, in the Western Pacific Ocean and intensified into a strong typhoon the next day. The typhoon landed in Hualian, Taiwan, on August 7 with a maximum wind of Level $13(40 \mathrm{~m} / \mathrm{s})$. On August 9 at 16:00, the typhoon landed in Fujian, Mainland China, with the maximum wind in the centre being Level $12(33 \mathrm{~m} / \mathrm{s})$. Then, the typhoon was reduced into a tropical storm on the night of August 9. This typhoon was characterised by high intensity, long influence time, wide range, and low movement speed. The typhoon's path is shown in Figure 1.

The measured site was at the top of a construction engineering building in Wenzhou University. The site was surrounded by hills in the east and south and open plains in the west and north. The building was about $8 \mathrm{~m}$ high and was in the suburb of the city. The roughness was classified as Class III in accordance with China's regulations [35]. Two WJ-3 anemometers were set on the top of the construction engineering building at the same height. The anemometers were installed on $9 \mathrm{~m}$ high straight poles to avoid disturbance in the wind field. The transverse distance between the two straight poles was $17 \mathrm{~m}$, and the distance from the anemometer to the ground was $30 \mathrm{~m}$. The two anemometers collected wind speed synchronously at a sampling frequency of $20 \mathrm{~Hz}$. The arrangement of the anemometers is shown in Figure 2 [36]. The specific parameters of the anemometers are shown in Table 1.

\section{Data Processing Method}

The real-time sampling period was from 22:00 on August 9, 2009, to 12:00 on August 11,2009, and involved a total of 42 


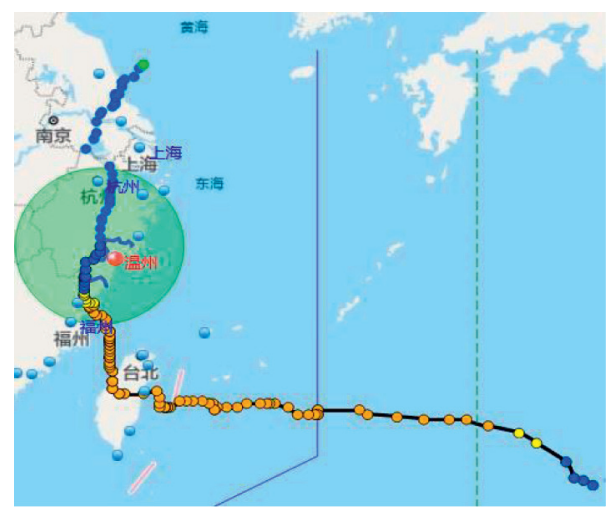

Figure 1: Route of Typhoon Morakot.
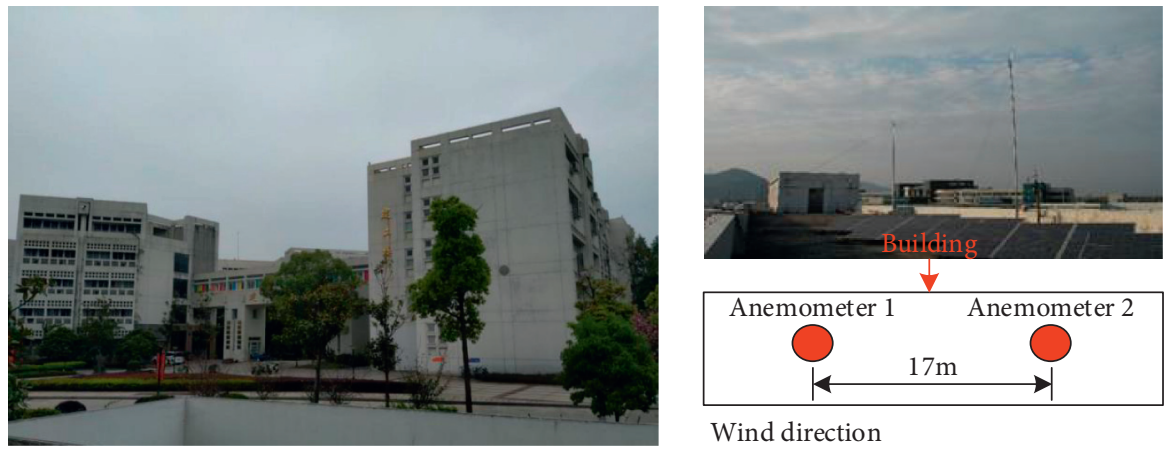

Wind direction<smiles>CC(C)(F)C#N</smiles>

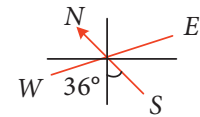

(a)

(b)

FIGURE 2: Anemometers layout.

TABle 1: Specific parameters of the WJ-3 anemometers.

\begin{tabular}{lc}
\hline Project & Value \\
\hline Measurement range of wind speed & $0 \sim 60 \mathrm{~m} / \mathrm{s}$ \\
Measurement accuracy of wind speed & $\pm 0.4 \mathrm{~m} / \mathrm{s}$ \\
Start-up wind speed & $\leq 0.8 \mathrm{~m} / \mathrm{s}$ \\
Resolution of wind speed & $0.1 \mathrm{~m} / \mathrm{s}$ \\
Measurement range of wind direction & $0 \sim 359.9^{\circ}$ \\
Measurement accuracy of wind direction & $\pm 2^{\circ}$ \\
Resolution of wind direction & $1^{\circ}$ \\
Input voltage & $\mathrm{AC} 220 \mathrm{~V} \pm 10 \%(50 \mathrm{~Hz})$ \\
Transmission mode & $\mathrm{RS} 485$ \\
Transmission distance & $1 \mathrm{kM}$ \\
Displayed contents & Instantaneous wind speed/direction, 2-minute mean wind speed/direction, \\
\hline
\end{tabular}

hours. The sample was divided by using $10 \mathrm{~min}$ as the basic time interval in accordance with regulations [35].

3.1. Mean Wind Speed and Direction. The measured sample includes two time series, namely, wind speed and wind direction. Wind speed has two components in the horizontal direction, namely, $u_{x}(t)$ and $u_{y}(t)$. The expression is as follows:

$$
\begin{aligned}
& u_{y}(t)=u(t) \sin \phi(t), \\
& u_{x}(t)=u(t) \cos \phi(t),
\end{aligned}
$$

where $u(t)$ and $\phi(t)$ refer to wind speed series and wind direction series, respectively.

With $10 \mathrm{~min}$ as the basic time interval, mean wind speed $U$ and horizontal wind angle $\phi$ were calculated via vector decomposition. The expression is as follows: 


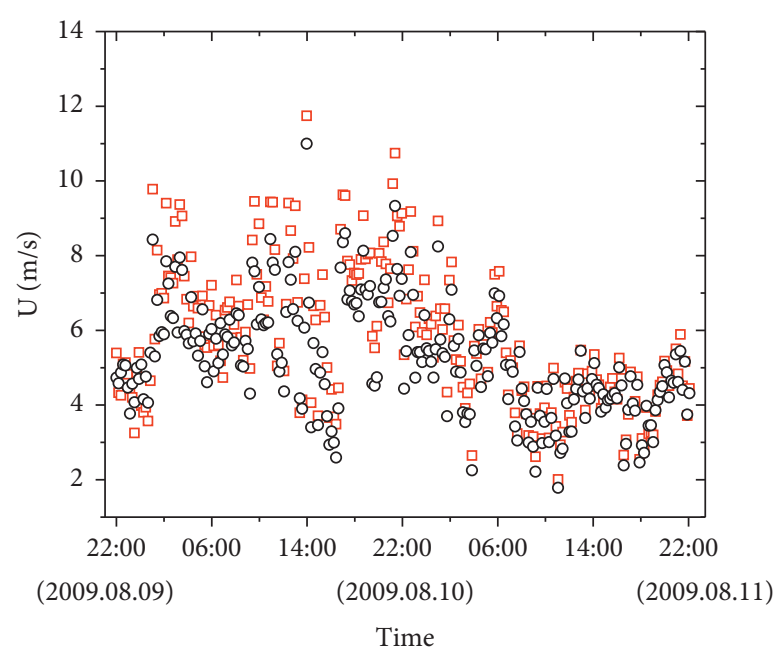

口 Measuring point 1

- Measuring point 2

(a)

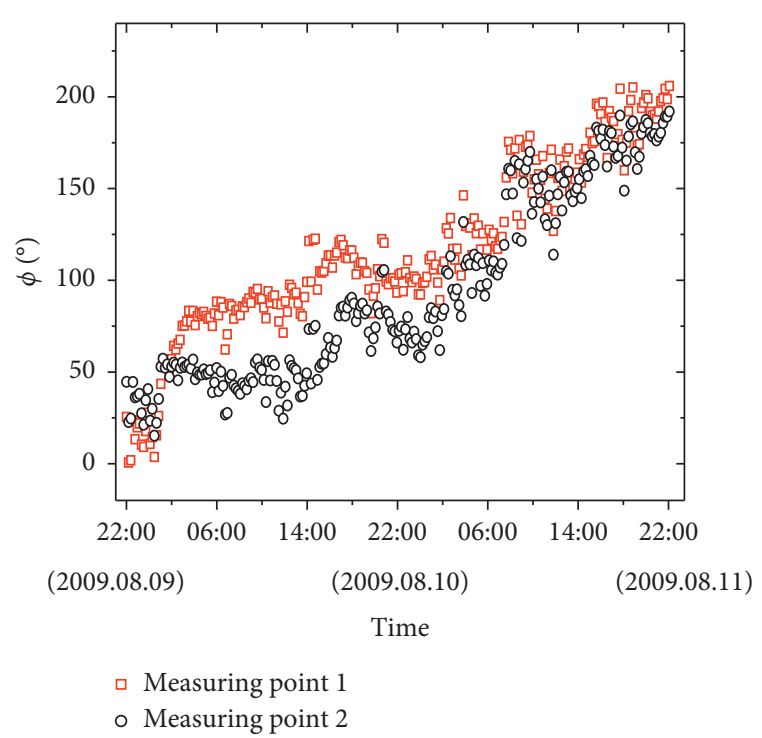

(b)

Figure 3: (a) Mean wind speed varying with time. (b) Angle of wind direction varying with time.

$$
\begin{aligned}
U & =\sqrt{{\overline{u_{x}(t)}}^{2}+{\overline{u_{y}(t)}}^{2}}, \\
\cos \phi & =\frac{\overline{u_{x}(t)}}{U}
\end{aligned}
$$

where $\overline{u_{x}(t)}$ and $\overline{u_{y}(t)}$ refer to the mean wind speeds of $u_{x}(t)$ and $u_{y}(t)$, respectively, at $10 \mathrm{~min}$.

\subsection{Power Spectral Density of Fluctuating Wind Speed}

3.2.1. Auto-Power Spectrum. The turbulence power spectrum represents the distribution of turbulence energy in the frequency domain and can describe the characteristics of fluctuating wind accurately. Its general expression can be written as follows [37]:

$$
\frac{S_{u}(f)}{u^{2}}=\frac{A}{\left(1+B f^{\beta}\right)^{\gamma}},
$$

where $f$ refers to Monin coordinate and $A, B, \beta$, and $\gamma$ refer to four parameters.

Previous field measurements and wind tunnel test results have indicated that the Von Karman spectrum can accurately reflect the characteristics of fluctuating wind. The functional expression of the power spectral density of longitudinal fluctuating wind is as follows [38]:

$$
S_{u}(n)=\frac{\overline{2{u^{\prime 2}}^{x}} L_{u}^{x}}{\bar{U}\left[1+\left(2 c n L_{u}^{x} / \bar{U}\right)^{2}\right]^{5 / 6}},
$$

where $\bar{U}$ refers to the mean wind speed; $L_{u}^{x}$ refers to the integral scale of longitudinal turbulence; $\overline{u^{\prime 2}}$ refers to the variance of longitudinal fluctuating wind speed; $n$ is the frequency of longitudinal fluctuating wind; and $c$ is 4.2065 .

The functional expression of the power spectral density of horizontal and vertical wind can be obtained based on the hypothesis of isotropic turbulence as follows:

$$
S_{v}(n)=S_{w}(n)=\frac{1}{2}\left[S_{u}(n)-\frac{n \mathrm{~d} S_{u}(n)}{\mathrm{d} n}\right] .
$$

For isotropic turbulence, $L_{v}^{x}=L_{w}^{x}=0.5 L_{u}^{x}$. The final expression of the Karman spectrum is obtained as follows:

$$
\begin{aligned}
& \text { for the horizontal: } \frac{n S_{u}(n)}{\sigma_{u}^{2}}=\frac{4 f}{\left(1+70.8 f^{2}\right)^{5 / 6}}, \\
& \text { for the vertical: } \frac{n S_{i}(n)}{\sigma_{i}^{2}}=\frac{4 f\left(1+755.2 f^{2}\right)}{\left(1+283.2 f^{2}\right)^{11 / 6}},
\end{aligned}
$$

where $\sigma_{i}^{2}$ is the variance of fluctuating wind speed component along $i$ direction.

3.2.2. Cross-Power Spectrum. Research on the cross-power spectrum of the fluctuating wind speed of near-ground wind is rare. Kaimal et al. [39] derived the expression of the crosspower spectrum of longitudinal and vertical fluctuating wind speed by using well-conditioned experimental wind data:

$$
\frac{-n C_{u w}(n)}{U_{0}^{* 2}}=\frac{14 f}{(1+9.6 f)^{2.4}},
$$

where $C_{u w}$ refers to the cross-power spectrum, $U_{0}^{*}$ refers to friction speed, and $f$ refers to Moin coordinates. Equation (7) is modified to obtain the expression of the cross-power 


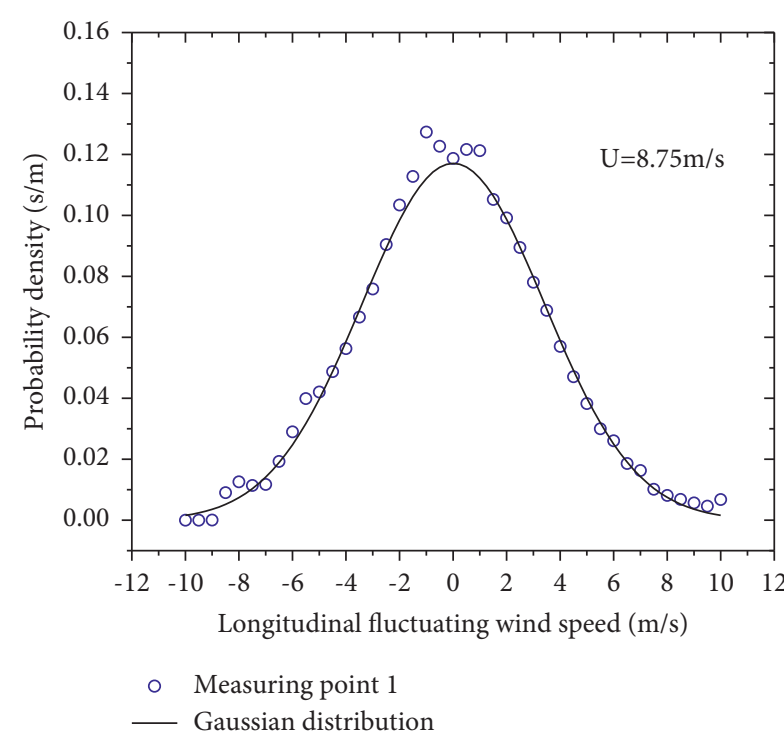

(a)

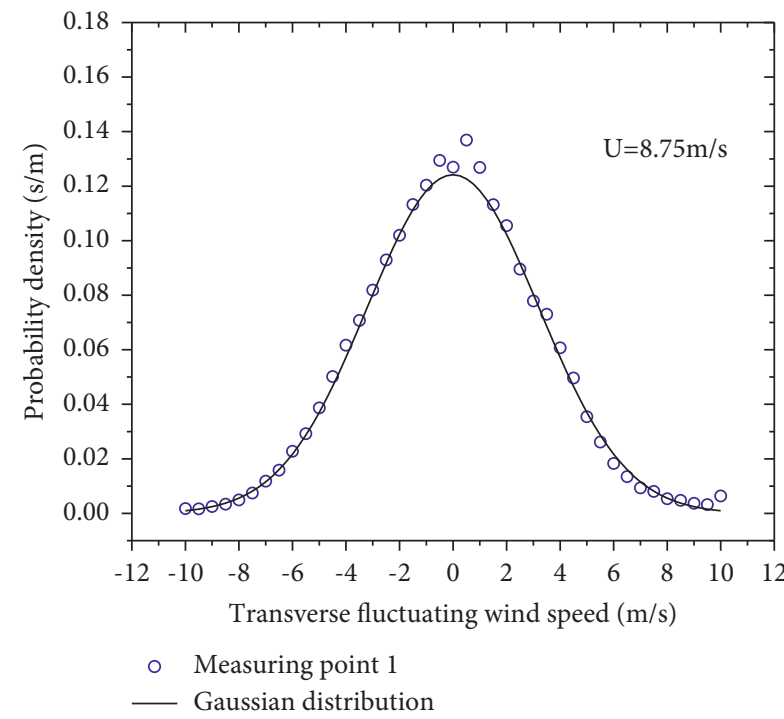

(c)

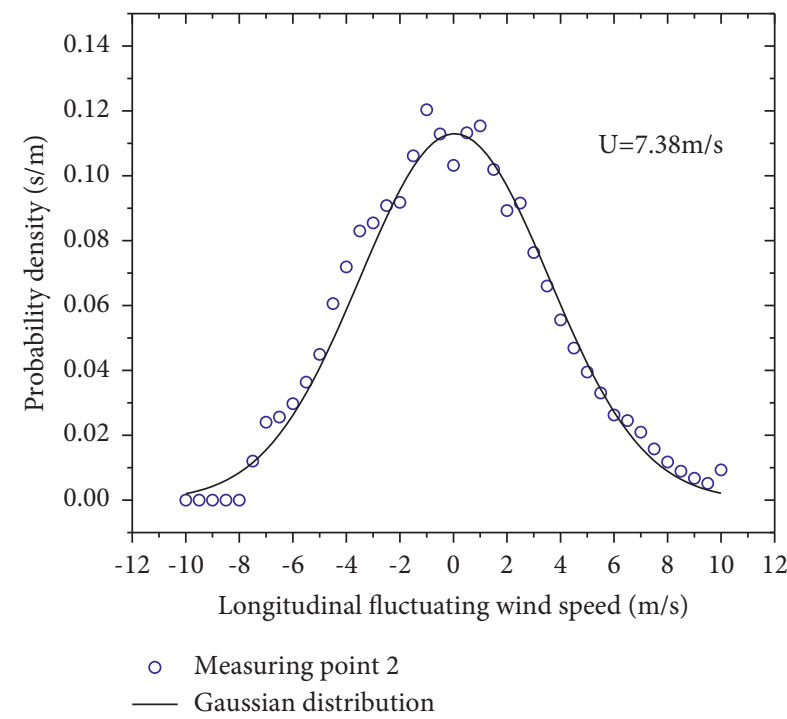

(b)

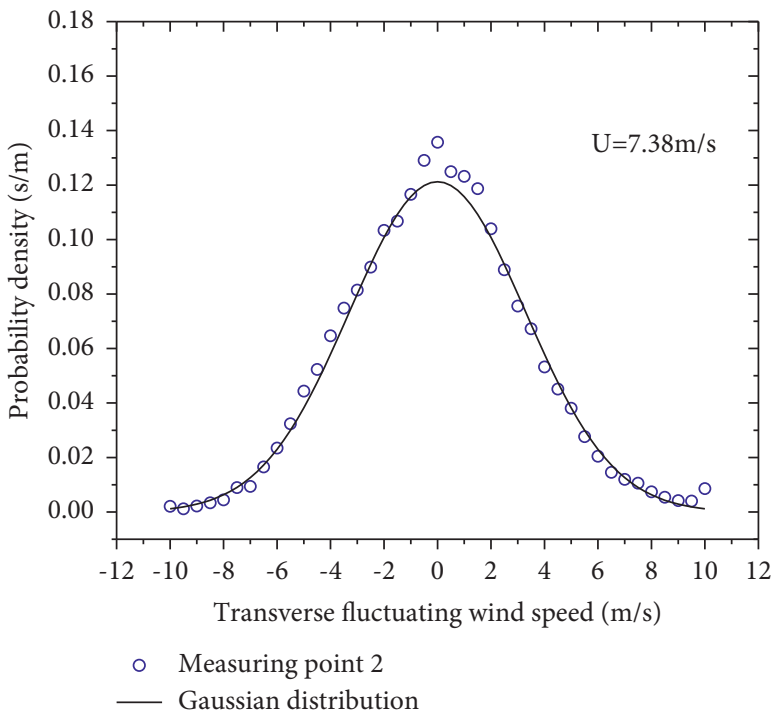

(d)

FIGURE 4: Probability density distribution of fluctuating wind speed. (a) Probability density of longitudinal fluctuating wind speed at point 1. (b) Probability density of longitudinal fluctuating wind speed at point 2. (c) Probability density of transverse fluctuating wind speed at point 1. (d) Probability density of transverse fluctuating wind speed at point 2 .

spectrum of longitudinal and transverse fluctuating wind speed.

$$
\frac{-n C_{u w}(n)}{\sigma_{u}^{2}}=\frac{a f}{(1+b f)^{c}}
$$

where $\sigma_{u}$ is equal to $2.5 U_{0}^{*}$. Parameters $a, b$, and $c$ are obtained by fitting and processing the sample at a $10 \mathrm{~min}$ time interval based on equation (8).

3.3. Autocorrelation Analysis. The dependence between the instantaneous value of a signal at one time and the instantaneous value at another time is called autocorrelation; it reflects the correlation between the values of the same sequence at different times. If $X(t)$ refers to a time series, then the expression of the correlation function is as follows:

$$
R_{X X}\left(t_{1}, t_{2}\right)=E\left[X\left(t_{1}\right) X\left(t_{2}\right)\right] .
$$

If $X(t)$ refers to a stationary stochastic process, then

$$
R_{X X}(\tau)=E[X(t) X(t+\tau)],
$$

where $R_{X X}$ refers to the autocorrelation function and $\tau$ refers to the time difference.

3.4. Coherence Analysis. The correlation between signals in the frequency domain is expressed by coherence. Davenport [40] proposed an empirical expression of the coherence 


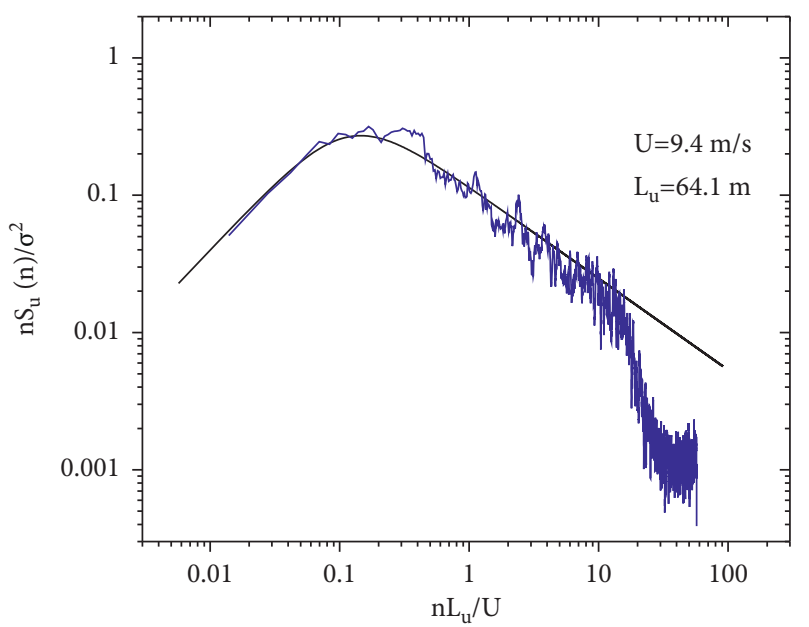

- Von Karman empirical spectrum — Measured power spectrum

(a)

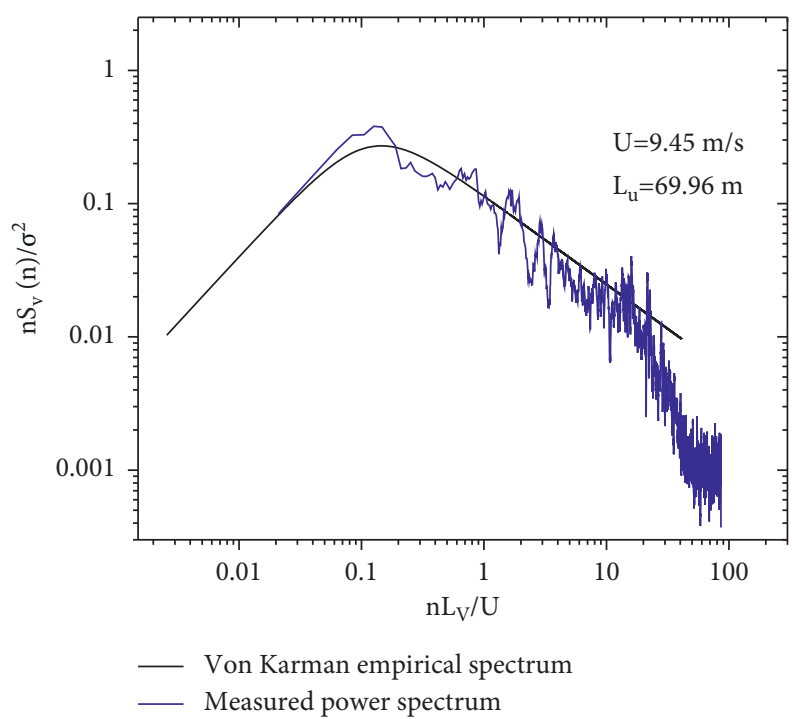

(c)

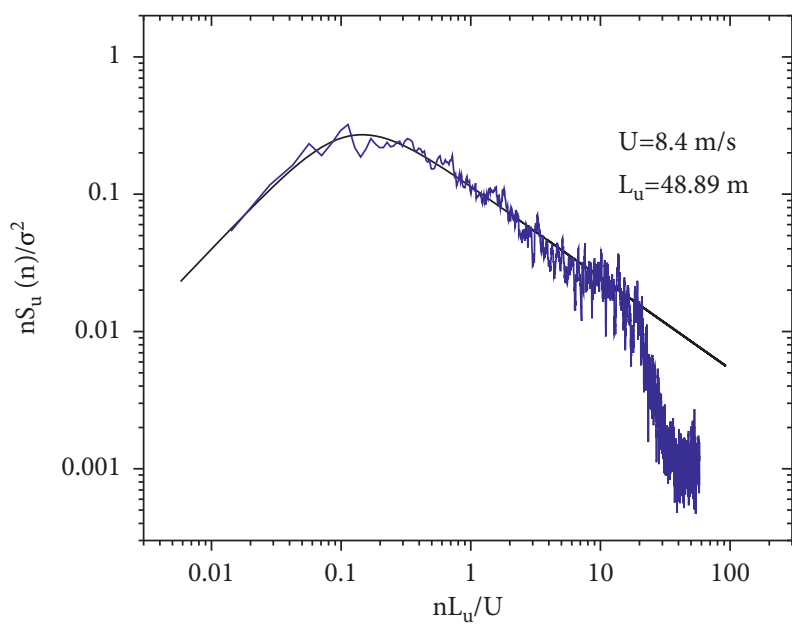

_ Von Karman empirical spectrum

— Measured power spectrum

(b)

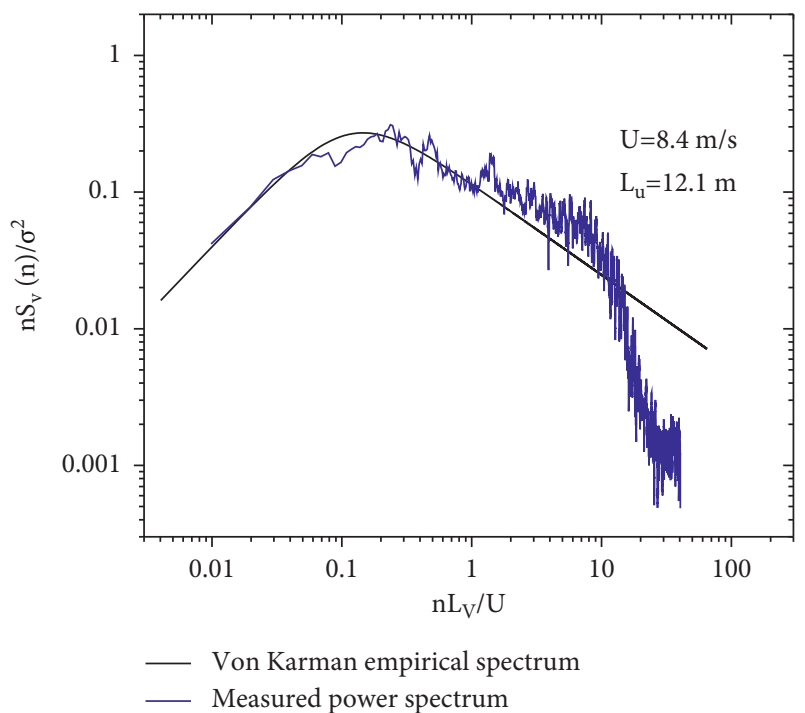

(d)

Figure 5: Power spectrum of fluctuating wind speed. (a) Measuring point 1, longitudinal. (b) Measuring point 2, longitudinal. (c) Measuring point 1, transverse. (d) Measuring point 2, transverse.

coefficient of the fluctuating wind speed component in the form of an exponential function as follows:

$$
\operatorname{Coh}(f)=\exp \left[-\frac{f}{U}\left(C_{z}^{2} \Delta z^{2}+C_{y}^{2} \Delta y^{2}\right)^{1 / 2}\right]
$$

where $f$ refers to the frequency; $U$ refers to the mean wind speed; $C_{y}$ and $C_{z}$ refer to the index attenuation coefficients in horizontal and vertical directions, respectively; $\Delta y$ and $\Delta z$ refer to the horizontal and vertical distances between signal measuring points, respectively; and Coh refers to the coherence coefficient.

In this study, if $\Delta y=0$, then equation (11) can be simplified as follows:

$$
\operatorname{Coh}(f)=\exp \left(-\frac{f}{U} C_{z} \Delta z\right)
$$

\section{Results and Discussion}

4.1. Mean Wind Speed and Angle of Wind Direction. In this study, the due north is $0^{\circ}$ of the angle of wind direction, and the clockwise direction is positive. Figures 3(a) and 3(b) show the changing curves of the mean wind speed and angle of wind direction of two measuring points on the east and west, respectively, over $10 \mathrm{~min}$. The mean wind speed and angle of wind direction of the two measuring points varying with time were consistent. From 22:00 on August 9, 2009, the mean wind speed increased with time and peaked at 14:00 on August 10. The maximum wind speeds at the eastern and western measuring points were 11.75 and $10.99 \mathrm{~m} / \mathrm{s}$, respectively. The mean wind speed decreased with time. The angle of wind direction varied 


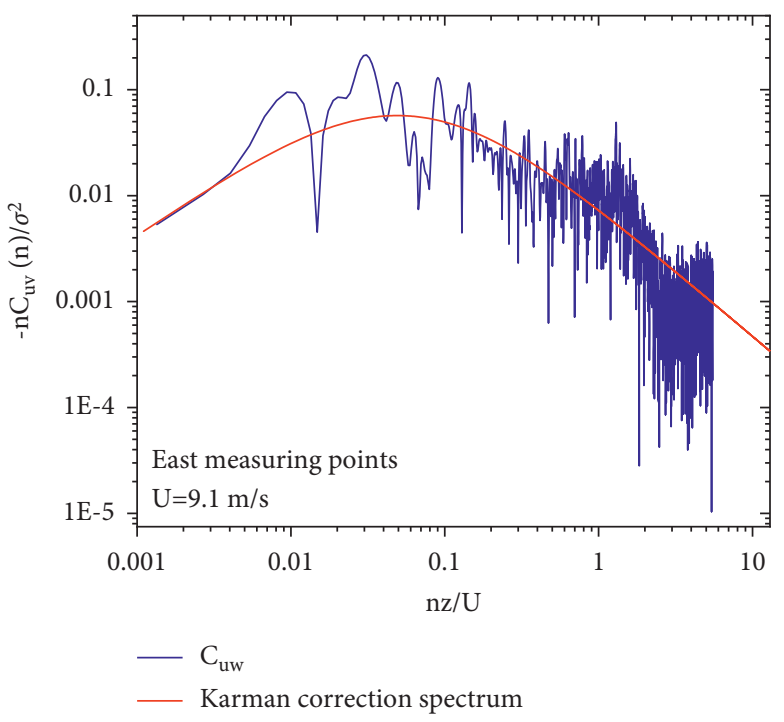

(a)

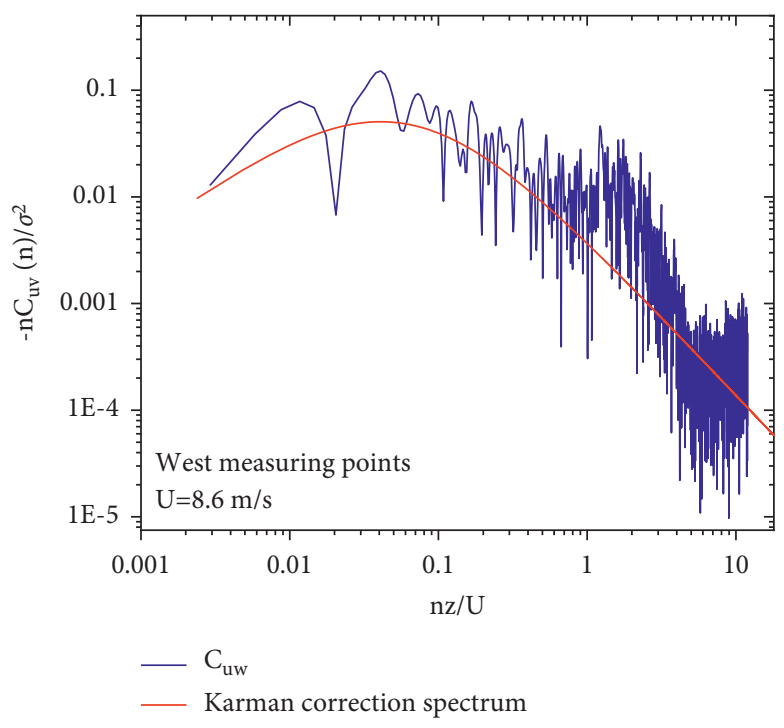

(b)

Figure 6: Cross-power spectrum of fluctuating wind speed. (a) Measuring point 1. (b) Measuring point 2.

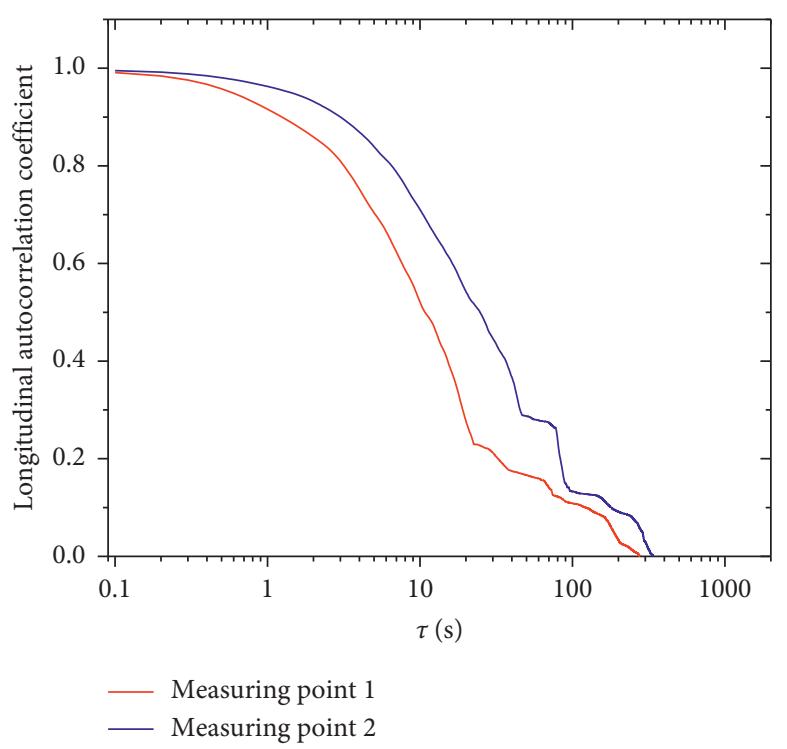

(a)

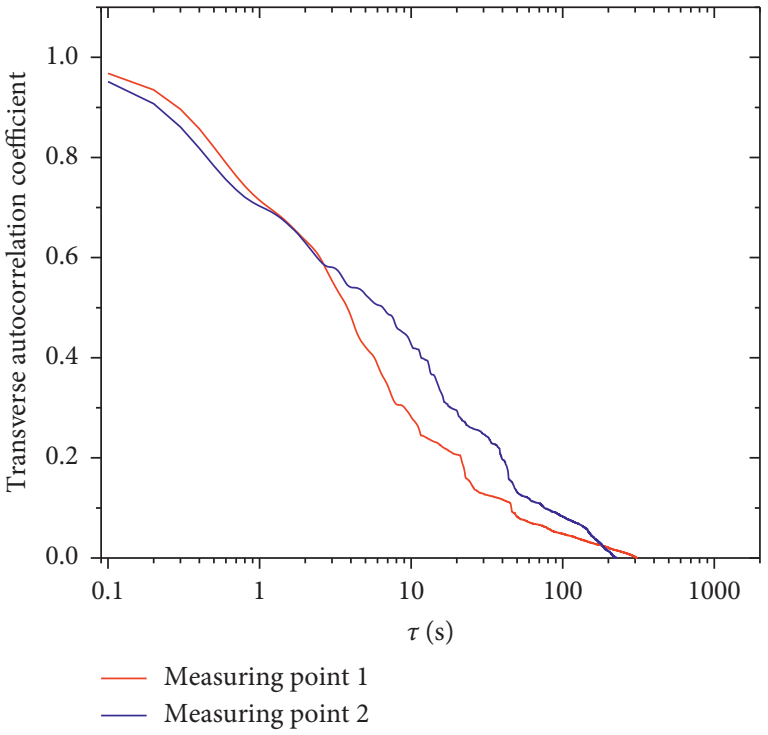

(b)

FIgURe 7: Autocorrelation coefficient varying with time interval. (a) Longitudinal autocorrelation coefficient varying with time interval. (b) Transverse autocorrelation coefficient varying with time interval.

greatly at $14: 00$. Figure $3(a)$ shows that the wind speed at that moment varied significantly, indicating that the typhoon gradually approached the measuring point, and the angle of wind direction gradually increased. Comparison of the wind speed and wind direction at both measuring points revealed that the mean wind speed of the eastern measuring point was slightly larger than that of the western measuring point. The difference at the peak value was $0.76 \mathrm{~m} / \mathrm{s}$. The angle of wind direction in the eastern measuring point was larger than that in the western measuring point, and the maximum difference was $22.87^{\circ}$.
4.2. Probability Density Distribution. The probability density function of fluctuating wind speed usually follows Gaussian distribution. Figure 4 shows the probability density distribution diagrams of longitudinal and transverse fluctuating wind speeds at measuring points 1 and 2 to determine whether the fluctuating wind speed follows Gaussian distribution under typhoon action. The Gaussian function distribution curve was obtained via moment estimation. The results showed that the probability density distribution of fluctuating wind speed in longitudinal and transverse directions approximately followed the Gaussian distribution, indicating that the probability density distribution of the 


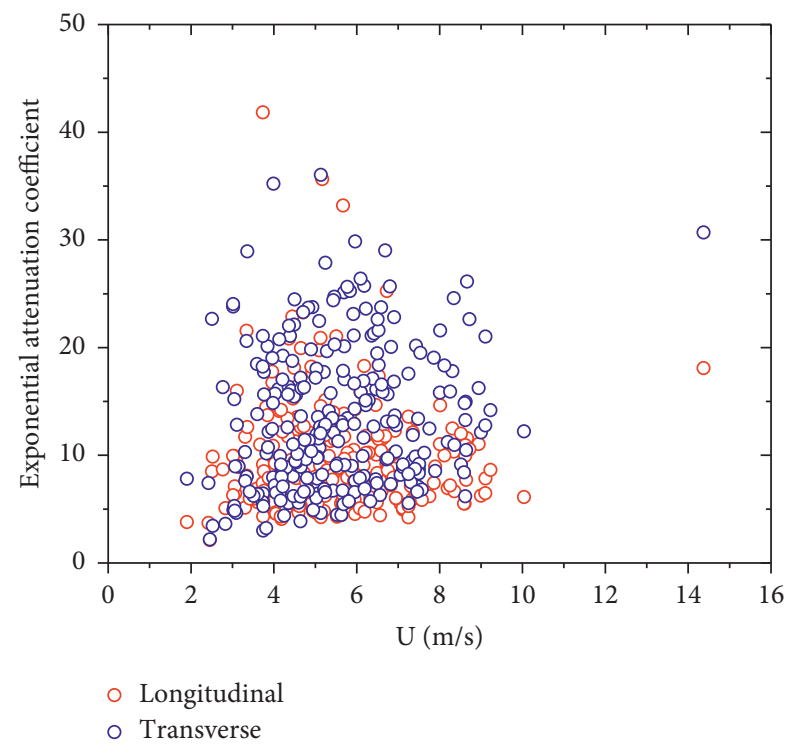

FIgURE 8: Exponential attenuation coefficient varying with the mean wind speed.

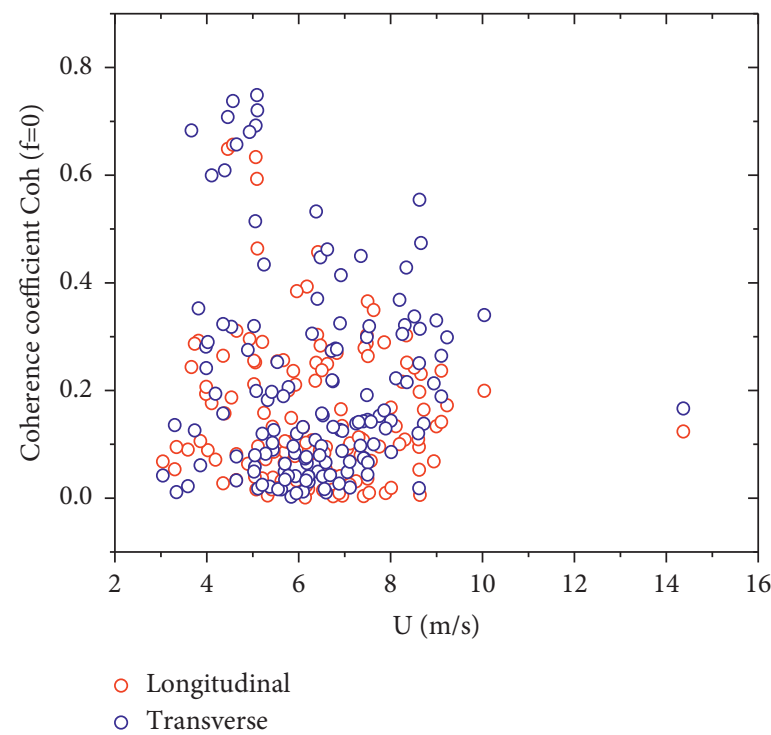

FIGURE 9: Coherence coefficient varying with the mean wind speed.

fluctuating wind speed of this typhoon followed the Gaussian distribution.

4.3. Auto-Power Spectrum. Figure 5 shows power spectrum curves of fluctuating wind speed at measuring points 1 and 2 . The Von Karman empirical spectrum is also provided for comparison. The results show that the power spectrum curve of longitudinal fluctuating wind speed coincided with the Von Karman empirical spectrum better than the power spectrum curve of transverse fluctuating wind speed did. The power spectrum curves of longitudinal and transverse fluctuating wind speeds coincided with the Von Karman empirical spectrum at a low frequency. However, at a high frequency, the measured power spectrum was smaller than the
Von Karman empirical spectrum. Overall, the fluctuating wind power spectrum of this typhoon was in good agreement with the Von Karman empirical spectrum, which shows that the Von Karman empirical spectrum can be used to describe the fluctuating wind power spectrum change rule of this typhoon.

4.4. Cross-Power Spectrum. Figure 6 shows the cross-power spectrum of fluctuating wind speed in longitudinal and transverse directions at measuring points 1 and 2. A fitting analysis was conducted on the measured data on the basis of equation (7). The fitting parameters $(a, b$, and $c)$ of the Karman correction spectrum at measuring point 1 were 6.36 , 34.75 , and 2.21. The fitting parameters $(a, b$, and $c)$ of the Karman correction spectrum at measuring point 2 were 4.47 , 


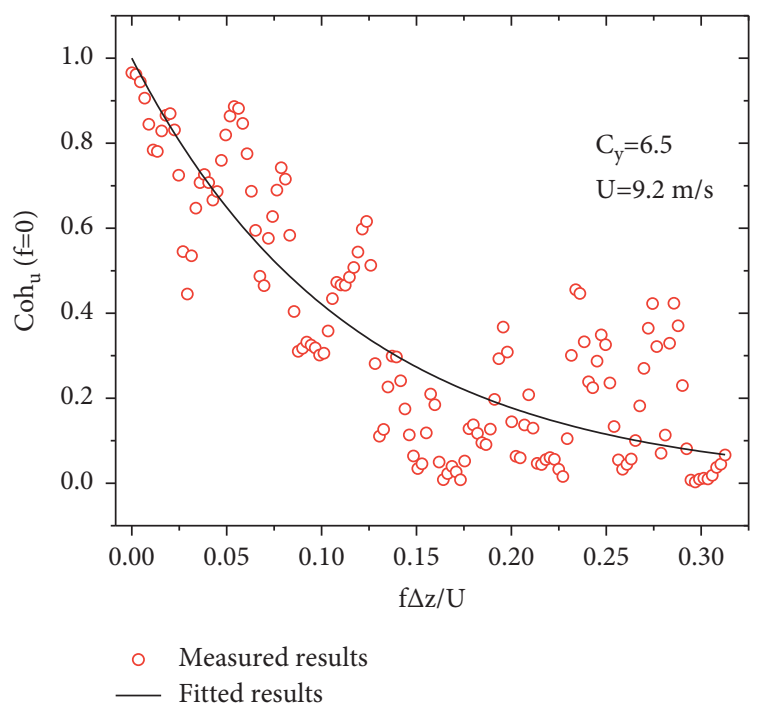

(a)

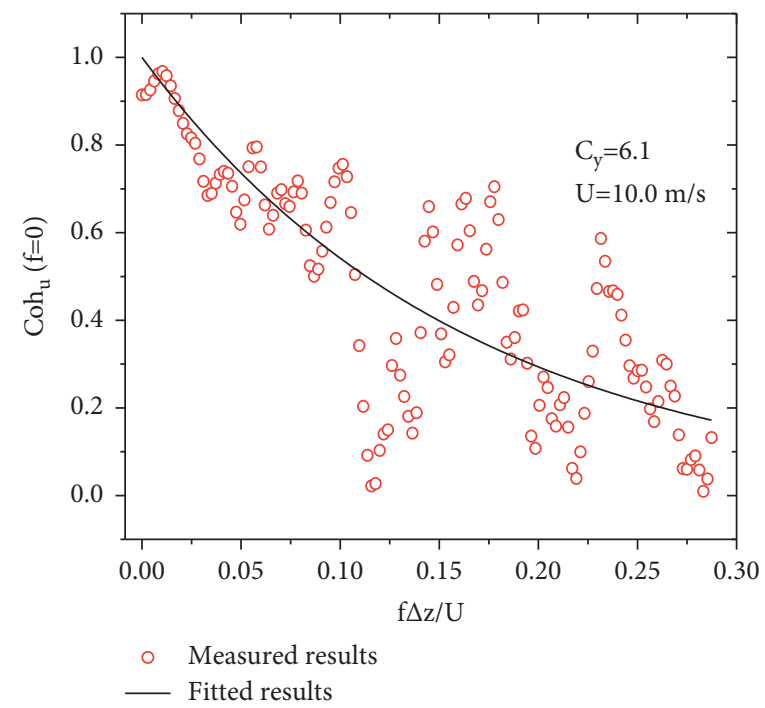

(b)

Figure 10: Coherence coefficient curves of the longitudinal fluctuating wind speed component in different wind speed periods.

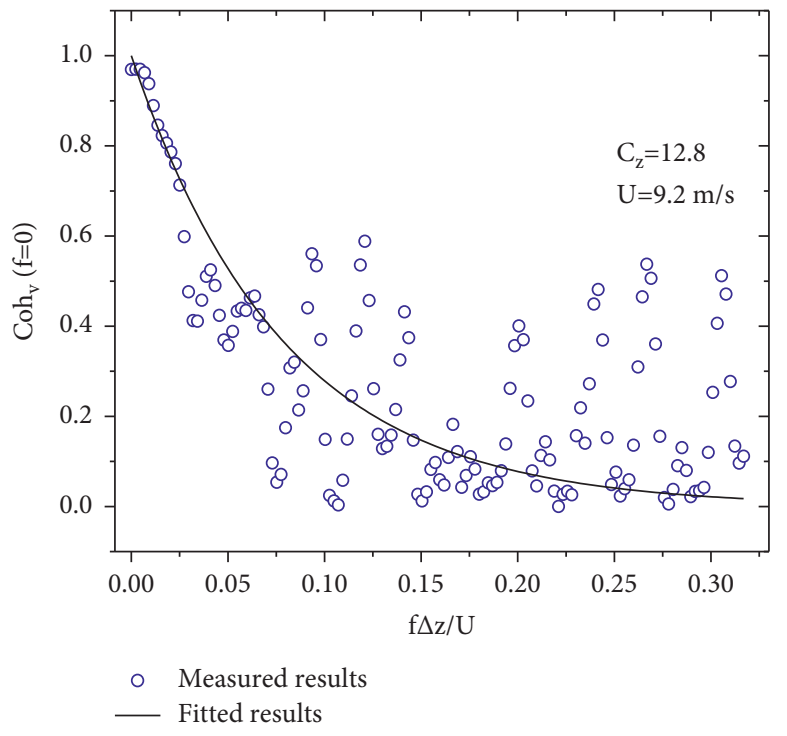

(a)

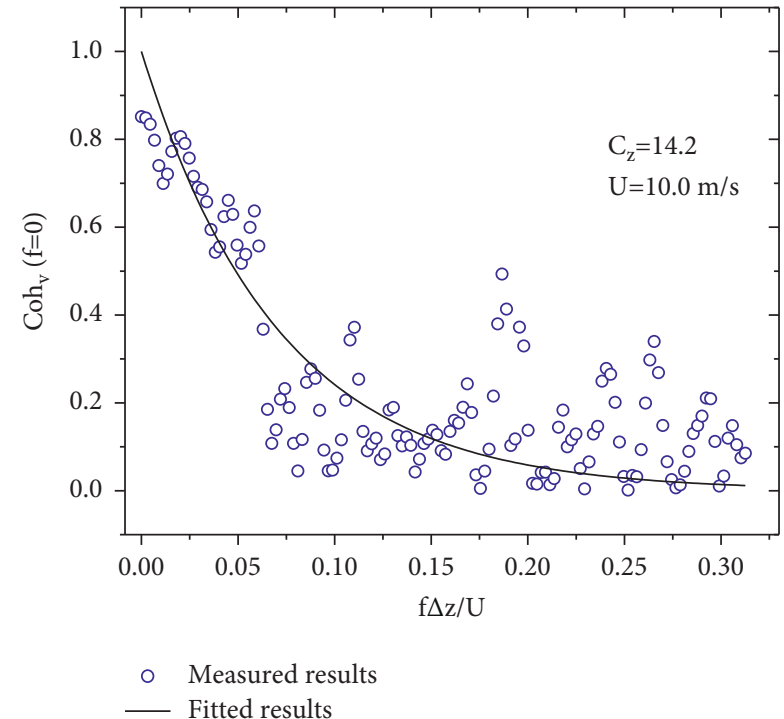

(b)

Figure 11: Coherence coefficient curves of the transverse fluctuating wind speed component in different wind speed periods.

16.59, and 2.48. The fitting parameters of the Karman correction spectrum were unaffected by the position of the measuring point. The corresponding Karman correction spectrum is provided in this paper for comparison. The results show that the measured cross-power spectrum of fluctuating wind speed was in good agreement with the Karman correction spectrum; thus, the Karman correction spectrum is also in good agreement with the variation law of the cross-power spectrum of fluctuating wind speed of this typhoon.

4.5. Correlation Analysis. Figure 7 shows the autocorrelation curves of longitudinal and transverse fluctuating wind speeds at measuring points 1 and 2 . The variation trends of the autocorrelation coefficients of longitudinal and transverse fluctuating wind speeds were the same. The autocorrelation coefficients of longitudinal fluctuating wind speed at the two measuring points differed obviously. The longitudinal autocorrelation coefficient at measuring point 2 was larger than that in the transverse direction. The autocorrelation coefficient decreased with the increase in $\tau$. Notably, the longitudinal autocorrelation coefficient decayed rapidly with the increase in $\tau$, whereas the transverse autocorrelation coefficient decayed at a constant rate.

4.6. Coherence. The coherence of fluctuating wind speed components was also analysed. Figure 8 shows the change in the exponential attenuation coefficient of longitudinal and 
transverse fluctuating wind speed components with the average wind speed. The exponential attenuation coefficients of longitudinal and transverse fluctuating wind speed components increased with the increase in the mean wind speed, and the distribution became increasingly discrete. The mean values of the exponential attenuation coefficients of longitudinal and transverse fluctuating wind speed components were 10.86 and 15.33, respectively, which are larger than the values in the research of Cao et al. [30] and Hui et al. [41]. Figure 9 shows the variations of the coherence coefficients of the longitudinal and transverse fluctuating wind speed components with the mean wind speed. The variations of the coherence coefficients of the two components with the mean wind speed were consistent. With the increase in the mean wind speed, the coherence coefficient decreased gradually and eventually stabilised at 0.1 .

The coherence coefficients of the longitudinal and transverse fluctuating wind speed components were compared with the fitting curves of exponential functions. Figures 10 and 11 show the coherence coefficient distribution of the longitudinal and transverse fluctuating wind speed components in different wind speed periods and the corresponding exponential function fitting curves. The measured results of the coherence coefficients of the longitudinal and transverse fluctuating wind speed components were in good agreement with the exponential function. This finding indicates that equation (12) is suitable for describing the coherence coefficients of the fluctuating wind speed components of this typhoon at eastern and western measuring points.

\section{Conclusions}

The characteristics of the wind field of Typhoon Morakot, including mean wind speed, turbulence intensity, gust factor, power spectrum density, and coherence, were analysed by using data measured by two anemometers placed on the top of a construction engineering building in Wenzhou University $(30 \mathrm{~cm}$ high from the ground). The following conclusions were obtained:

(1) The probability density of fluctuating wind speed in longitudinal and transverse directions approximately followed the Gaussian distribution, indicating that the probability density distribution of the fluctuating wind speed of this typhoon exhibited a Gaussian distribution.

(2) The power spectrum curve of longitudinal fluctuating wind speed coincided with the Von Karman empirical spectrum better than that of transverse fluctuating wind speed did. The power spectrum curves of longitudinal and transverse fluctuating wind speeds coincided with the Von Karman empirical spectrum well at a low frequency. However, at a high frequency, the measured power spectrum was smaller than the Von Karman empirical spectrum. In general, the fluctuating wind power spectrum of this typhoon was consistent with the Von Karman empirical spectrum. Thus, the Von Karman empirical spectrum can be used to describe the fluctuating wind power spectrum change rule of this typhoon.
(3) A fitting analysis of the measured data was conducted based on equation (10). $a, b$, and $c$ fitting parameters of the Karman correction spectrum in the east measuring point were $6.36,34.75$, and 2.21, respectively; $a, b$, and $c$ fitting parameters of the Karman correction spectrum in the east measuring point were $6.21,32.57$, and 2.42 , respectively. The fitting parameters of the Karman correction spectrum were unaffected by the position of the measuring point. The corresponding Karman correction spectrum was provided in this paper for comparison. The measured cross-power spectrum of fluctuating wind speed was in good agreement with the Von Karman correction spectrum. This result indicates that the Von Karman correction spectrum is in good agreement with the variation law of the cross-power spectrum of fluctuating wind speed of this typhoon.

(4) The variation trends of the autocorrelation coefficients of longitudinal and transverse fluctuating wind speeds were the same. The autocorrelation coefficients of longitudinal fluctuating wind speed at the two measuring points differed obviously. The longitudinal autocorrelation coefficient at measuring point 2 was larger than that in the transverse direction. The autocorrelation coefficient decreased with the increase in $\tau$. Notably, the longitudinal autocorrelation coefficient decayed rapidly with the increase in $\tau$, whereas the transverse autocorrelation coefficient decayed at a constant rate.

(5) The exponential attenuation coefficients of longitudinal and transverse fluctuating wind speed components increased with the increase in the mean wind speed, and the distribution became increasingly discrete. The mean values of the exponential attenuation coefficients of longitudinal and transverse fluctuating wind speed components were 10.86 and 15.33 , respectively, which are larger than the findings of Cao and Hui. The variations of the coherence coefficients of the longitudinal and transverse fluctuating wind speed components with the mean wind speed were consistent. With the increase in the mean wind speed, the coherence coefficient decreased gradually and eventually stabilised at 0.1 . The measured results of the coherence coefficients of the longitudinal and transverse fluctuating wind components were consistent with the exponential function.

(6) The fluctuating wind field based on the stationary theory can be simulated by the fluctuating wind spectrum model, but the simulation of the nonstationary wind field based on the nonstationary evolution power spectrum is still difficult and needs further analyses and research studies.

\section{Data Availability}

Some or all data, models, or code generated or used during the study are available from the corresponding author by request. 


\section{Conflicts of Interest}

The authors declare that they have no conflicts of interest.

\section{Acknowledgments}

The paper was supported by Zhejiang Province Natural Science Foundation Project (LY19E080022), Natural Science Foundation of China (51508419 and 51678455), and Zhejiang Provincial Department of Education Project (The title of the Project: Wind Field Characteristic Monitoring and Wind Load Monitoring Research on Coastal Low-rise Buildings, and the number: Y202147409).

\section{References}

[1] B. Wang, F. Hu, and X. Cheng, "Wind gust and turbulence statistics of typhoons in south China," Acta Meteorologica Sinica, vol. 25, no. 1, pp. 113-127, 2011.

[2] S. Y. Cao, Y. J. Ge, and Y. Tamura, "Wind damage in China caused by typhoon Rananim," in Proceedings of the 6th Asia-Pacific Conference on Wind Engineering, Seoul, Korea, September 2005.

[3] W. H. Shi, Z. N. Li, and C. X. Zhang, "Field measurements of strong wind characteristics near ground in Wenzhou district," Journal of Building Structures, vol. 31, no. 10, pp. 34-40, 2010.

[4] H. Wang, A. Li, T. Guo, and J. Xie, "Field measurement on wind characteristic and buffeting response of the Runyang suspension bridge during typhoon Matsa," Science in China-Series E: Technological Sciences, vol. 52, no. 5, pp. 13541362, 2009.

[5] L. Song, J. Pang, C. Jiang, H. Huang, and P. Qin, "Field measurement and analysis of turbulence coherence for typhoon nuri at Macao friendship bridge," Science China Technological Sciences, vol. 53, no. 10, pp. 2647-2657, 2010.

[6] K. J. Eaton and J. R. Mayne, "The measurement of wind pressures on two-storey houses at Aylesbury," Journal of Wind Engineering and Industrial Aerodynamics, vol. 1, pp. 67-109, 1975.

[7] P. R. Sparks, G. T. Reid, W. D. Reid, S. Welsh, and N. Welsh, "Wind conditions in hurricane Hugo by measurement, inference, and experience," Journal of Wind Engineering and Industrial Aerodynamics, vol. 41, no. 1-3, pp. 55-66, 1992.

[8] N. Kato, T. Ohkuma, J. R. Kim, H. Marukawa, and Y. Niihori, "Full-scale measurements of wind velocity in two urban areas using an ultrasonic anemometer," Journal of Wind Engineering and Industrial Aerodynamics, vol. 41, no. 1-3, pp. 67-78, 1992.

[9] W. F. Huang and Y. L. Xu, "Prediction of typhoon design wind speed and profile over complex terrain," Structural Engineering \& Mechanics, vol. 45, no. 1, pp. 1-18, 2013.

[10] S. Cao, T. Wang, Y. Ge, and Y. Tamura, "Numerical study on turbulent boundary layers over two-dimensional hills-effects of surface roughness and slope," Journal of Wind Engineering and Industrial Aerodynamics, vol. 104-106, pp. 342-349, 2012.

[11] E. V. Laitone, "Wind tunnel tests of wings at Reynolds numbers below 70 000," Experiments in Fluids, vol. 23, no. 5, pp. 405-409, 1997.

[12] G. Diana and S. Omarini, "A non-linear method to compute the buffeting response of a bridge validation of the model through wind tunnel tests," Journal of Wind Engineering and Industrial Aerodynamics, vol. 201, Article ID 104163, 2020.
[13] J. Zhang, M. Zhang, B. Huang, Y. Li, J. Yu, and F. Jiang, "Wind tunnel test on local wind field around the bridge tower of a truss girder," Advances in Civil Engineering, vol. 2021, Article ID 8867668, 13 pages, 2021.

[14] T. Tamura, A. Okuno, and Y. Sugio, "LES analysis of turbulent boundary layer over 3D steep hill covered with vegetation," Journal of Wind Engineering and Industrial Aerodynamics, vol. 95, no. 9-11, pp. 1463-1475, 2007.

[15] S. Murakami and A. Mochida, "3-D numerical simulation of airflow around a cubic model by means of the k- $\epsilon$ model," Journal of Wind Engineering and Industrial Aerodynamics, vol. 31, no. 2-3, pp. 283-303, 1988.

[16] S. Murakami, A. Mochida, and K. Hibi, "Three-dimensional numerical simulation of air flow around a cubic model by means of large eddy simulation," Journal of Wind Engineering and Industrial Aerodynamics, vol. 25, no. 3, pp. 291-305, 1987.

[17] A. Baghaei Daemei, E. M. Khotbehsara, E. M. Nobarani, and P. Bahrami, "Study on wind aerodynamic and flow characteristics of triangular-shaped tall buildings and CFD simulation in order to assess drag coefficient," Ain Shams Engineering Journal, vol. 10, no. 3, pp. 541-548, 2019.

[18] L. Cochran and R. Derickson, "A physical modeler's view of Computational Wind Engineering," Journal of Wind Engineering and Industrial Aerodynamics, vol. 99, no. 4, pp. 139-153, 2011.

[19] Y. L. Li, X. T. Cai, K. Tang, and H. Liao, "Study of spatial distribution feature of wind fields over bridge site with a deepcutting gorge using numerical simulation," China Civil Engineering Journal, vol. 44, no. 2, pp. 116-122, 2011.

[20] Y. Li, X. Xu, M. Zhang, and Y. Xu, "Wind tunnel test and numerical simulation of wind characteristics at a bridge site in mountainous terrain," Advances in Structural Engineering, vol. 20, no. 8, pp. 1223-1231, 2017.

[21] M. Zhang, Y. Li, B. Wang, and S. Ren, "Numerical simulation of wind characteristics at bridge site considering thermal effects," Advances in Structural Engineering, vol. 21, no. 9, pp. 1313-1326, 2018.

[22] M. Zhang, J. Zhang, Y. Li, J. Yu, J. Zhang, and L. Wu, "Wind characteristics in the high-altitude difference at bridge site by wind tunnel tests," Wind and Structures, vol. 30, no. 6, pp. 547-558, 2020.

[23] J. M. L. Mattuella, A. M. Loredo-Souza, M. G. K. Oliveira, and A. P. Petry, "Wind tunnel experimental analysis of a complex terrain micrositing," Renewable and Sustainable Energy Reviews, vol. 54, pp. 110-119, 2016.

[24] Y. Li, P. Hu, X. Xu, and J. Qiu, "Wind characteristics at bridge site in a deep-cutting gorge by wind tunnel test," Journal of Wind Engineering and Industrial Aerodynamics, vol. 160, pp. 30-46, 2017.

[25] Z. S. Chen, K. T. Tse, K. C. S. Kwok, A. Kareem, and B. Kim, "Measurement of unsteady aerodynamic force on a galloping prism in a turbulent flow: a hybrid aeroelastic-pressure balance," Journal of Fluids and Structures, vol. 102, Article ID 103232, 2021.

[26] Z. S. Chen, H. L. Huang, Y. M. Xu, K. T. Tse, B. Kim, and Y. Wang, "Unsteady aerodynamics on a tapered prism under forced excitation," Engineering Structures, vol. 240, Article ID 112387, 2021.

[27] Z. S. Chen, X. Z. Fu, Y. M. Xu, K. T. Tse, B. Kim, and Y. Cruz, "A perspective on the aerodynamics and aeroelasticity of tapering: partial reattachment," Journal of Wind Engineering and Industrial Aerodynamics, vol. 212, Article ID 104590, 2021. 
[28] J. Y. Fu, J. R. Wu, A. Xu, Q. S. Li, and Y. Q. Xiao, "Full-scale measurements of wind effects on guangzhou west tower," Engineering Structures, vol. 35, pp. 120-139, 2012.

[29] P. Huang, Y. T. Dai, X. Wang, and M. Gu, "Field measurement on power spectra and coherence characteristics of nearground wind in shanghai coastal area," Engineering $\mathrm{Me}$ chanics, vol. 31, no. 4, pp. 126-133, 2014.

[30] S. Cao, Y. Tamura, N. Kikuchi, M. Saito, I. Nakayama, and Y. Matsuzaki, "Wind characteristics of a strong typhoon," Journal of Wind Engineering and Industrial Aerodynamics, vol. 97, no. 1, pp. 11-21, 2009.

[31] T. Miyata, H. Yamada, H. Katsuchi, and M. Kitagawa, "Fullscale measurement of akashi-kaikyo bridge during typhoon," Journal of Wind Engineering and Industrial Aerodynamics, vol. 90, no. 12, pp. 1517-1527, 2001.

[32] J. P. Pang, Z. X. Lin, and G. Y. Jun, "Field measurements of strong wind characteristics near ground in Pudong district," Experiments \& Measurements in Fluid Mechanics, 2002.

[33] J. B. Pang, Z. X. Lin, and Y. J. Ge, "Field measurements of strong wind characteristics near ground in Pudong district," in Proceedings of the 9th National Conference on Atmospheric Environment and Pollution, Shanghai, China, September 2012.

[34] Q. S. Li, Y. M. Dai, Z. N. Li, and S. Hu, "Surface layer wind field characteristics during a severe typhoon 'Hagupit' landfalling," Journal of Building Structures, vol. 31, no. 4, pp. 58-65, 2010.

[35] China Architecture \& Building Press, Load Code for the Design of Building Structures, GB 50009-2012, China Architecture \& Building Press, Beijing, China.

[36] W. H. Shi, Field Measurements of Wind Field and Wind Load Characteristics on Low and High-Rise Building, Hunan university, Hunan, China, 2013.

[37] P. J. Richards, R. P. Hoxey, and J. L. Short, "Spectral models for the neutral atmospheric surface layer," Journal of Wind Engineering and Industrial Aerodynamics, vol. 87, no. 2-3, pp. 167-185, 2000.

[38] T. von Karman, "Progress in the statistical theory of turbulence," Proceedings of the National Academy of Sciences, vol. 34, no. 11, pp. 530-539, 1948.

[39] J. C. Kaimal, J. C. Wyngaard, Y. Izumi, and O. R. Coté, Spectral characteristics of surface-layer turbulence," Quarterly Journal of the Royal Meteorological Society, vol. 98, no. 417, pp. 563-589, 1972.

[40] A. G. Davenport, "The spectrum of horizontal gustiness near the ground in high winds," Quarterly Journal of the Royal Meteorological Society, vol. 87, no. 372, pp. 194-211, 1961.

[41] M. C. H. Hui, A. Larsen, and H. F. Xiang, "Wind turbulence characteristics study at the Stonecutters bridge site: part II: wind power spectra, integral length scales and coherences," Journal of Wind Engineering and Industrial Aerodynamics, vol. 97, no. 1, pp. 48-59, 2009. 